J Am Chem Soc. 2016 April 6; 138(13): 4310-4313. doi:10.1021/jacs.6b00936.

\title{
Potentiometric Measurements of Semiconductor Nanocrystal Redox Potentials
}

\author{
Gerard M. Carroll, Carl K. Brozek, Kimberly H. Hartstein, Emily Y. Tsui, and Daniel R. \\ Gamelin* \\ Department of Chemistry, University of Washington, Seattle, Washington 98195-1700, United \\ States
}

\begin{abstract}
A potentiometric method for measuring redox potentials of colloidal semiconductor nanocrystals (NCs) is described. Fermi levels of colloidal $\mathrm{ZnO}$ NCs are measured in situ during photodoping, allowing correlation of $\mathrm{NC}$ redox potentials and reduction levels. Excellent agreement is found between electrochemical and optical redox-indicator methods. Potentiometry is also reported for colloidal CdSe NCs, which show more negative conduction-band-edge potentials than in $\mathrm{ZnO}$. This difference is highlighted by spontaneous electron transfer from reduced CdSe NCs to ZnO $\mathrm{NCs}$ in solution, with potentiometry providing a measure of the inter-NC electron-transfer driving force. Future applications of NC potentiometry are briefly discussed.
\end{abstract}

The redox potentials of colloidal semiconductor nanocrystals (NCs) play central roles in many current and envisioned technologies. For example, electron-transfer (ET) kinetics and reaction spontaneity for NC-sensitized solar photocatalysis are governed by the redox potentials of the NC photoabsorbers. ${ }^{1-6}$ Likewise, relative potentials of band-like and surface-trapped electronic configurations dictate $\mathrm{NC}$ electronic doping, ${ }^{7}$ which governs the utility of NCs for electronic and optoelectronic technologies such as photovoltaics. 8,9 Although critical for many target applications, in situ measurements of colloidal NC redox potentials have proven challenging.

Cyclic voltammetry (CV) is the most commonly employed electrochemical technique for measuring colloidal NC redox potentials. ${ }^{10-12}$ Irreversibility of NC CV waves, low currentto-NC ratios, redox-active surface states, and surface-composition inhomogeneities have all been found to complicate solution-phase NC electrochemistry. CV measurements of NCs immobilized on electrode surfaces have been successful, ${ }^{12-15}$ but NC redox potentials are very sensitive to their surface chemistry, ${ }^{16,17}$ and the redox potentials of the same NCs as free-standing colloids may therefore differ substantially. As a consequence of these complications, it is common for driving forces of ET reactions involving colloidal semiconductor NCs to be discussed in terms of band-edge potentials estimated from vacuum

\footnotetext{
*Corresponding Author: gamelin@chem.washington.edu.

The authors declare no competing financial interest.

Supporting Information

The Supporting Information is available free of charge on the ACS Publications website at DOI: 10.1021/jacs.6b00936.

Experimental details and data (PDF)
} 
ionization and electron-affinity measurements, often of the corresponding bulk material. Although this approach has powerful intuitive value, observations ${ }^{16,18}$ that altering surface ligation alone can shift $\mathrm{NC}$ band edges by as much as $1 \mathrm{eV}$ highlight the need for in situ redox measurements of colloidal NCs in their native form. Here, we report a potentiometric method for measuring colloidal NC redox potentials. Potentiometry has been a valuable tool in metal nanoparticle research. ${ }^{19}$ By coupling potentiometry with optical detection of conduction-band (CB) electrons in colloidal semiconductor NCs generated via photodoping, ${ }^{20,21}$ redox potentials associated with these electrons can be deduced. As a simple proof of concept, we show that our colloidal CdSe NCs have CB-edge potentials more negative than our $\mathrm{ZnO} \mathrm{NCs}$, leading to spontaneous inter-NC ET from photoreduced CdSe NCs to ZnO NCs in solution. Additional mechanistic details are revealed by the transient open-circuit potentials.

Figure 1 illustrates the apparatus used to measure Fermi levels $\left(E_{\mathrm{F}}\right)$ during NC photodoping. In an airtight optical cuvette, solutions of $\mathrm{NCs}$ under $\mathrm{N}_{2}$ atmosphere are photoreduced using hole quenchers. ${ }^{7}$ The average number of $\mathrm{CB}$ electrons per $\mathrm{NC}(\langle n\rangle)$ is quantified during photodoping using absorption spectroscopy. Simultaneously, electrodes in the NC solution track changes in $E_{\mathrm{F}}$ under galvanostatic $(I=0 \mathrm{~A})$ control, i.e., the potentiostat biases the working electrode in response to the photoinduced increase in $E_{\mathrm{F}}$ (Figure 1, right). The electrode and solution $E_{\mathrm{F}}$ remain equivalent at all times. Consequently, no depletion region at the electrode/electrolyte interface develops, and the recorded half-cell potential represents $E_{\mathrm{F}}$ of the NC suspension. ${ }^{19}$ From these combined data, NC redox potentials at various electron densities can be determined. Accurate transient potentiometry requires a stable reference electrode. We use a leakless $\mathrm{Ag} / \mathrm{AgCl}$ reference electrode, which avoids instabilities due to solution contamination, ionic activity, or electrode/electrolyte junction potentials (see Supporting Information (SI)). To account for possible electrochemical drift, $\mathrm{CVs}$ of an internal standard (cobaltocenium hexafluorophosphate, $\left[\mathrm{Cp}_{2} \mathrm{Co}\right]\left[\mathrm{PF}_{6}\right]$ ) were collected before and after most experiments. Drift was generally very small $(<\sim 10 \mathrm{mV})$. All data are referenced experimentally to the ferrocenium/ferrocene couple $\left(\mathrm{Fc}^{+} / \mathrm{Fc}\right.$, see $\left.\mathrm{SI}\right)$.

Figure $2 \mathrm{~A}$ plots $E_{\mathrm{F}}$ and the absorbance at $\lambda=1000 \mathrm{~nm}\left(A_{1000}\right)$ measured simultaneously during $\mathrm{ZnO} \mathrm{NC}$ photodoping using ethanol as the hole quencher. ${ }^{22,23} A_{1000}$ increases with $\mathrm{ZnO}$ photoexcitation, reflecting photodoping. ${ }^{21,24-26}$ Concomitantly, $E_{\mathrm{F}}$ becomes more negative. From the per-electron extinction at $\lambda=1000 \mathrm{~nm}\left(\varepsilon_{1000}=1097\langle n\rangle^{0.7} \mathrm{M}^{-1} \mathrm{~cm}^{-1}\right.$, see $\mathrm{SI}),\langle n\rangle \approx 20 \mathrm{e}^{-}{ }_{\mathrm{CB}} / \mathrm{NC}$ at its maximum $\left(\left\langle n_{\max }\right\rangle\right)$, corresponding to an average electron density of $\left\langle N_{\max }\right\rangle \approx 1.21 \times 10^{20} \mathrm{~cm}^{-3}$, in agreement with previous reports. ${ }^{7,21,23,26}$ Because $E_{\mathrm{F}}$ and $A_{1000}$ were measured simultaneously, it is valuable to plot $E_{\mathrm{F}}$ against $\langle n\rangle$ as shown in Figure $2 \mathrm{~B}$. $E_{\mathrm{F}}$ rises steeply at $\sim-70 \mathrm{mV} /\langle n\rangle$ between $\langle n\rangle=0$ and 2, after which its rise decreases to $\sim-4 \mathrm{mV} /\langle n\rangle$ until photodoping is complete.

It is instructive to compare these potentiometric data with those obtained using a solvated optical redox indicator (ORI), ${ }^{1-3}$ an approach we applied recently to monitor $\mathrm{ZnO} \mathrm{NC}$ photodoping. ${ }^{27}$ Here, $E_{\mathrm{F}}$ is measured during photodoping using the optically detected equilibrium constant of a solvated redox couple that is also in equilibrium with the NCs. For the present comparison, ORI data were collected while photodoping the same $\mathrm{ZnO}$ NCs as probed electrochemically, under the same experimental conditions, and the ratio 
$\left[\mathrm{Cp}_{2} \mathrm{Co}^{+}\right] /\left[\mathrm{Cp}_{2} \mathrm{Co}\right]$ measured spectrophotometrically to determine $E_{\mathrm{F}}$. These results are included in Figure 2B. The two methods yield nearly indistinguishable results.

Despite yielding the same results, potentiometry offers an important advantage over the ORI method: Potentiometry circumvents the need for a transparent spectroscopic window in which to monitor the ORI (e.g., for $\mathrm{Cp}_{2} \mathrm{Co}, \lambda_{\text {probe }} \approx 500 \mathrm{~nm}$ ). Because of this advantage, the redox potentials of narrower-gap NCs can be readily monitored potentiometrically, making this the more general approach. As proof of concept, potentiometry and absorption were measured simultaneously during photodoping of CdSe NCs (with absorption overlapping that of $\mathrm{Cp}_{2} \mathrm{Co}$ ). Figure $3 \mathrm{~A}$ plots electronic absorption spectra of undoped and maximally photodoped $d=4.1 \mathrm{~nm}$ CdSe NCs, photoexcited at $405 \mathrm{~nm}$ in the presence of $\mathrm{Na}\left[\mathrm{Et}_{3} \mathrm{BH}\right]$ (hole quencher), ${ }^{20,28}\left[\mathrm{Bu}_{4} \mathrm{~N}\right]\left[\mathrm{PF}_{6}\right]$ (electrolyte), and TOPO (NC stabilizer). Photodoping causes the first $\mathrm{NC}$ excitonic transition to bleach to $A / A_{0} \approx 0.3$ ( $A_{0}=$ absorbance before photodoping) and redshift slightly, consistent with prior results. ${ }^{20}$ From the established linear relationship between $\langle n\rangle$ and $A / A_{0},{ }^{20,29}$ these data imply $\left\langle n_{\max }\right\rangle=1.4$, again consistent with previous results. ${ }^{20,30}$ Note that the CdSe NC photodoping experiment is considerably quicker than the $\mathrm{ZnO} \mathrm{NC}$ photodoping experiment (Figure 2) because of $\sim 5$ times greater photoexcitation rates, greater conversion yields using $\left[\mathrm{Et}_{3} \mathrm{BH}\right]^{-}$hole quenchers, ${ }^{21}$ and smaller $\left\langle n_{\max }\right\rangle$ in the CdSe NCs.

Figure 3B plots $E_{\mathrm{F}}$ and $A / A_{0}$ data collected transiently during CdSe NC photodoping for two experiments: one performed with $\mathrm{Cp}_{2} \mathrm{Co}^{+}$as an electron shuttle and internal redox standard and the other without $\mathrm{Cp}_{2} \mathrm{Co}^{+}$. Prior to irradiation, $E_{\mathrm{F}}$ and $A / A_{0}$ are both constant, but $E_{\mathrm{F}}$ is $\sim 100 \mathrm{mV}$ more positive in the sample containing $\mathrm{Cp}_{2} \mathrm{Co}^{+}$. This difference reflects a small amount of $\mathrm{Cp}_{2} \mathrm{Co}^{+}$reduction prior to deliberate CdSe irradiation. ${ }^{31}$ Upon irradiation of the sample without $\mathrm{Cp}_{2} \mathrm{Co}^{+}, E_{\mathrm{F}}$ immediately shifts more negative, reaching a value near $-1.52 \mathrm{~V} \mathrm{vs} \mathrm{Fc}^{+} / \mathrm{Fc}$ after $4 \mathrm{~min}$. Similarly, $A / A_{0}$ decreases immediately, reaching a new value of $\sim 0.3$. Upon irradiation of the sample with $\mathrm{Cp}_{2} \mathrm{Co}^{+}, E_{\mathrm{F}}$ again immediately shifts more negative, reaching a similar value near $-1.52 \mathrm{~V} \mathrm{vs} \mathrm{Fc} / / \mathrm{Fc}$ after 4 min. Interestingly, the onset of CdSe photodoping (as indicated by the inflection in $A / A_{0}$ ) is clearly delayed by $\sim 40$ $\mathrm{s}$ in the presence of $\mathrm{Cp}_{2} \mathrm{Co}^{+}$, even though $E_{\mathrm{F}}$ starts shifting more negative immediately upon photoexcitation. This delayed photodoping reflects $E_{\mathrm{F}}$ equilibration between the CdSe NCs and $\mathrm{Cp}_{2} \mathrm{Co}^{+} / \mathrm{Cp}_{2} \mathrm{Co}$ redox couples, which initially strongly favors $\mathrm{Cp}_{2} \mathrm{Co}^{+}$reduction. Reduction of $\mathrm{Cp}_{2} \mathrm{Co}^{+}$by photodoped $\mathrm{CdSe}$ NCs continues until the $\mathrm{CdSe} \mathrm{CB}$-edge potential is reached, at which point both $\mathrm{Cp}_{2} \mathrm{Co}^{+}$reduction and $\mathrm{CdSe} \mathrm{NC}$ electron accumulation proceed simultaneously with further photoexcitation. This observation is an example of the new insights that can be gained from potentiometry in the time domain.

Figure 3C plots $E_{\mathrm{F}} \mathrm{vs}\langle n\rangle$ for both experiments of Figure 3B. Although $E_{\mathrm{F}}$ is very different for the two samples prior to photodoping, the onset of CdSe NC reduction occurs at $\sim-1.47$ $\mathrm{V}( \pm 0.01 \mathrm{~V})$ in both experiments. Once CB electrons begin to accumulate, the change in $E_{\mathrm{F}}$ between $\langle n\rangle=0$ and $\langle n\rangle=1$ is small, with a slope of $\sim 10 \mathrm{mV} /\langle n\rangle$. The slope of $E_{\mathrm{F}} \mathrm{vs}\langle n\rangle$ increases as $\left\langle n_{\max }\right\rangle$ is approached, and photodoping maximizes at $\left\langle n_{\max }\right\rangle \sim 1.4$ and $\sim 1.52$ $\mathrm{V}( \pm 0.01 \mathrm{~V})$ for both experiments. Plotted in this manner, the electrochemical data from these two experiments, which initially appeared markedly different (Figure 3B), are now 
essentially super-imposable. From this result we conclude that the CdSe CB-edge potential is independent of the presence of $\mathrm{Cp}_{2} \mathrm{Co}^{+}$under these conditions.

Comparing $E_{\mathrm{F}}$ data (Figures 2B and 3C), we note that the CdSe NCs at $\langle n\rangle=1$ are $\sim 260 \mathrm{mV}$ more reducing than the $\mathrm{ZnO} \mathrm{NCs}$ at $\langle n\rangle=1(-1.48 \mathrm{vs}-1.22 \mathrm{eV}$, respectively). This difference is notably smaller than would be estimated from bulk data $(\sim 1.1 \mathrm{eV}$, see SI), but it still indicates a driving force for inter-NC ET. To illustrate, a mixture of similar CdSe and $\mathrm{ZnO}$ NCs was prepared containing $\mathrm{Li}_{[}\left[\mathrm{Et}_{3} \mathrm{BH}\right]$ as the hole quencher, ${ }^{28}$ with all conditions similar to those of Figures 2 and 3. Figure 4 shows absorption spectra of this solution collected after selective CdSe photoexcitation for various durations. The broad NIR $(<2 \mathrm{eV})$ absorption characteristic of $n-\mathrm{ZnO}$ (Figure $2 \mathrm{~A}$ ) grows with photoexcitation time. The CdSe excitonic absorption maximum redshifts by $\sim 20 \mathrm{meV}$ over the same time window, but there is no evident bleach, allowing tentative attribution of this shift to a Stark effect associated with surface charge redistribution. Control experiments performed in the absence of $\mathrm{CdSe}$ $\mathrm{NCs}$ (see SI) show no spectroscopic changes, ruling out direct $\mathrm{ZnO}$ photodoping under these conditions. The absence of CdSe excitonic absorption bleach and growth of $\mathrm{ZnO}$ NIR absorbance indicate that photodoped CdSe NCs indeed transfer their electrons to ZnO NCs under these conditions, as anticipated from the favorable ET driving force measured electrochemically.

During the course of these experiments, several interesting complexities were noted. First, as anticipated from prior observations, ${ }^{16,18} \mathrm{CdSe} \mathrm{NC}$ redox potentials are found to be extraordinarily sensitive to sample preparation and measurement conditions, varying reproducibly by hundreds of $\mathrm{mV}$ depending on the specific details. Consequently, the redox potentials reported here reflect the particular reaction conditions employed, just as standard reduction potentials $\left(E^{\circ}\right)$ of molecular reagents correspond to a standard set of conditions. These observations will be described in detail in a subsequent report, but this preliminary observation already highlights the utility of this technique for identifying sample-specific redox potentials through in situ measurements. Additionally, we found it possible to measure the potentials of sub-CB electron traps in CdSe NCs by combining potentiometry with photoluminescence spectroscopy (PL, see $\mathrm{SI}$ ). Here, we observe PL brightening as $E_{\mathrm{F}}$ is raised, starting at least $120 \mathrm{mV}$ below the $\mathrm{CB}$ edge, before the characteristic darkening that coincides with $\mathrm{CB}$ filling and the resulting Auger recombination. ${ }^{20} \mathrm{NC}$ PL brightening at sub-CB potentials is consistent with several recent observations ${ }^{32-35}$ and indicates reductive passivation of surface electron traps. We note that in some cases CdSe NC surface-trap reduction appears to have exactly the opposite effect of quenching PL, ${ }^{18,20,36}$ reflecting the complexity of these surface chemistries and highlighting the need for in situ electrochemical measurements.

Overall, the results presented here demonstrate potentiometry as a powerful and broadly applicable approach to semiconductor NC electrochemistry. With this approach, it is possible to quantify band-edge potentials in situ, without special apparatus or modification of NC surface chemistries. The impact of NC composition (isovalent or aliovalent impurities, etc.), ${ }^{37-39}$ charge-compensating cations $\left(\mathrm{H}^{+}, \mathrm{Li}^{+},\left[\mathrm{CoCp}_{2}\right]^{+}\right.$, etc.), ${ }^{1,2,7,40}$ or $\mathrm{NC}$ surface ligands (with dipoles, conjugation, etc.) ${ }^{16,18,41}$ should be readily quantified, and extension to other redox-active $\mathrm{NC}$ heterostructures ${ }^{3,23}$ or nonphotochemical reductants 
appears equally promising. The transient potentiometry described by Figures 2 and 3 further suggests interesting possibilities for probing dynamical processes. NC potentiometry thus opens new opportunities for future fundamental and applied research involving redox-active colloidal semiconductor NCs.

\section{Supplementary Material}

Refer to Web version on PubMed Central for supplementary material.

\section{Acknowledgments}

This research was supported by the NSF (CHE-1506014 to DRG, Graduate Research Fellowship DGE-1256082 to KHH), NIH (Postdoctoral Fellowship F32GM1 10876 to EYT), and the State of Washington through the Clean Energy Institute via funding from the Washington Research Foundation (to CKB).

\section{References}

1. Dung D, Ramsden J, Grätzel M. J Am Chem Soc. 1982; 104:2977.

2. Nenadović MT, Rajh T, Mićić OI, Nozik AJ. J Phys Chem. 1984; 88:5827.

3. Jakob M, Levanon H, Kamat PV. Nano Lett. 2003; 3:353.

4. Huang J, Stockwell D, Huang Z, Mohler DL, Lian T. J Am Chem Soc. 2008; 130:5632. [PubMed: 18393497]

5. Han Z, Qiu F, Eisenberg R, Holland PL, Krauss TD. Science. 2012; 338:1321. [PubMed: 23138979]

6. Jensen SC, Homan SB, Weiss EA. J Am Chem Soc. 2016; 138:1591. [PubMed: 26784531]

7. Schimpf AM, Knowles KE, Carroll GM, Gamelin DR. Acc Chem Res. 2015; 48:1929. [PubMed: 26121552]

8. Ning Z, Voznyy O, Pan J, Hoogland S, Adinolfi V, Xu J, Li M, Kirmani AR, Sun JP, Minor J, Kemp KW, Dong H, Rollny L, Labelle A, Carey G, Sutherland B, Hill I, Amassian A, Liu H, Tang J, Bakr OM, Sargent EH. Nat Mater. 2014; 13:822. [PubMed: 24907929]

9. Chuang CHM, Brown PR, Bulović V, Bawendi MG. Nat Mater. 2014; 13:796. [PubMed: 24859641]

10. Haram SK, Quinn BM, Bard AJ. J Am Chem Soc. 2001; 123:8860. [PubMed: 11535097]

11. Inamdar SN, Ingole PP, Haram SK. Chem Phys Chem. 2008; 9:2574. [PubMed: 18956405]

12. Amelia M, Lincheneau C, Silvi S, Credi A. Chem Soc Rev. 2012; 41:5728. [PubMed: 22763461]

13. Kucur E, Riegler J, Urban GA, Nann T. J Chem Phys. 2003; 119:2333.

14. Querner C, Reiss P, Sadki S, Zagorska M, Pron A. Phys Chem Chem Phys. 2005; 7:3204. [PubMed: 16240033]

15. Vanmaekelbergh D, Liljeroth P. Chem Soc Rev. 2005; 34:299. [PubMed: 15778764]

16. Brown PR, Kim D, Lunt RR, Zhao N, Bawendi MG, Grossman JC, Bulović V. ACS Nano. 2014; 8:5863. [PubMed: 24824726]

17. Jeong KS, Deng Z, Keuleyan S, Liu H, Guyot-Sionnest P. J Phys Chem Lett. 2014; 5:1139. [PubMed: 26274461]

18. Wang C, Shim M, Guyot-Sionnest P. Science. 2001; 291:2390. [PubMed: 11264530]

19. Scanlon MD, Peljo P, Mendez MA, Smirnov E, Girault HH. Chem Sci. 2015; 6:2705.

20. Rinehart JD, Schimpf AM, Weaver AL, Cohn AW, Gamelin DR. J Am Chem Soc. 2013; 135:18782. [PubMed: 24289732]

21. Schimpf AM, Gunthardt CE, Rinehart JD, Mayer JM, Gamelin DR. J Am Chem Soc. 2013; 135:16569. [PubMed: 24050304]

22. Haase M, Weller H, Henglein A. J Phys Chem. 1988; 92:482.

23. Wood A, Giersig M, Mulvaney P. J Phys Chem B. 2001; 105:8810.

24. Shim M, Guyot-Sionnest P. Nature. 2000; 407:981. [PubMed: 11069172]

25. Shim M, Guyot-Sionnest P. J Am Chem Soc. 2001; 123:11651. [PubMed: 11716721] 
26. Liu WK, Whitaker KM, Smith AL, Kittilstved KR, Robinson BH, Gamelin DR. Phys Rev Lett. 2007; 98:186804. [PubMed: 17501594]

27. Carroll GM, Schimpf AM, Tsui EY, Gamelin DR. J Am Chem Soc. 2015; 137:11163. [PubMed: 26263400]

28. Prior work has established that photodoping using $\left[\mathrm{Et}_{3} \mathrm{BH}\right]^{-}$is largely independent of alkali metal countercation (ref 21).

29. Shim M, Wang C, Guyot-Sionnest P. J Phys Chem B. 2001; 105:2369.

30. To account for the possibility of residual baseline effects, the spectra in Figure 3A were also analyzed by Gaussian fitting (see SI), from which $\left\langle n_{\max }\right\rangle=1.3$ is estimated.

31. Partial reduction of $\mathrm{Cp}_{2} \mathrm{Co}^{+}$by $\mathrm{Na}\left[\mathrm{Et}_{3} \mathrm{BH}\right]$ was confirmed by optical detection of $\mathrm{Cp}_{2} \mathrm{Co}$ even in the absence of CdSe NCs (not shown). Only a small portion of $\mathrm{Cp}_{2} \mathrm{Co}^{+}$is reduced. This reduction likely involves an unidentified minority species in solution, because if direct reduction of $\mathrm{Cp}_{2} \mathrm{Co}^{+}$ by $\mathrm{Na}\left[\mathrm{Et}_{3} \mathrm{BH}\right]$ were possible, then it would be expected to be irreversible and proceed to completion. In the presence of CdSe NCs, some $\mathrm{Cp}_{2} \mathrm{Co}^{+}$reduction may also occur from inadvertent $\mathrm{CdSe}$ photoexcitation under normal handling conditions.

32. Jha PP, Guyot-Sionnest P. J Phys Chem C. 2010; 114:21138.

33. Galland C, Ghosh Y, Steinbruck A, Sykora M, Hollingsworth JA, Klimov VI, Htoon H. Nature. 2011; 479:203. [PubMed: 22071764]

34. Weaver AL, Gamelin DR. J Am Chem Soc. 2012; 134:6819. [PubMed: 22417458]

35. Rinehart JD, Weaver AL, Gamelin DR. J Am Chem Soc. 2012; 134:16175. [PubMed: 22985258]

36. Gooding AK, Gomez DE, Mulvaney P. ACS Nano. 2008; 2:669. [PubMed: 19206597]

37. Cohn AW, Kittilstved KR, Gamelin DR. J Am Chem Soc. 2012; 134:7937. [PubMed: 22515505]

38. Zhou D, Kittilstved KR. J Mater Chem C. 2015; 3:4352.

39. Schimpf AM, Lounis SD, Runnerstrom EL, Milliron DJ, Gamelin DR. J Am Chem Soc. 2015; 137:518. [PubMed: 25490191]

40. Valdez CN, Braten M, Soria A, Gamelin DR, Mayer JM. J Am Chem Soc. 2013; 135:8492. [PubMed: 23697709]

41. Frederick MT, Weiss EA. ACS Nano. 2010; 4:3195. [PubMed: 20503978] 

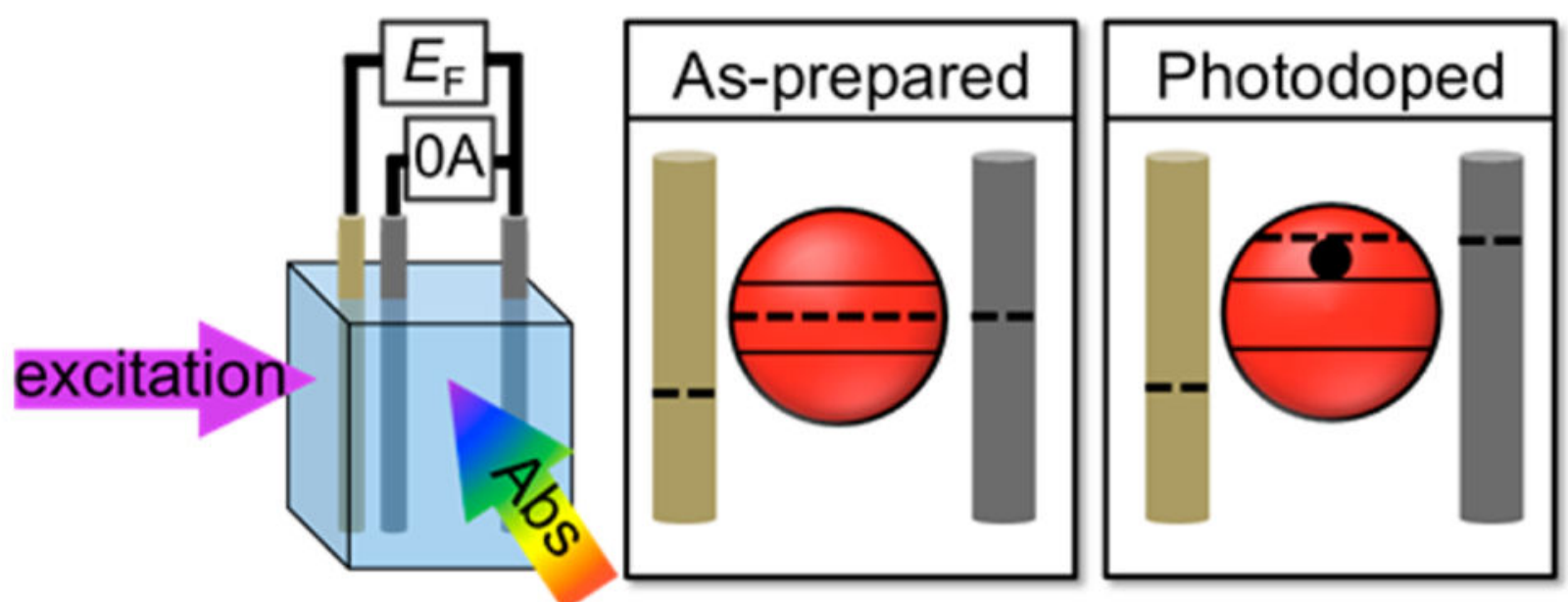

Figure 1.

Apparatus used to collect potentiometric and absorption data during colloidal NC photodoping (left). Set to $0 \mathrm{~A}$, the galvanostatic cell measures the solution potential during NC photodoping. NC absorption is measured simultaneously. The working electrode (gray) responds to changes in Fermi level upon NC photodoping. 

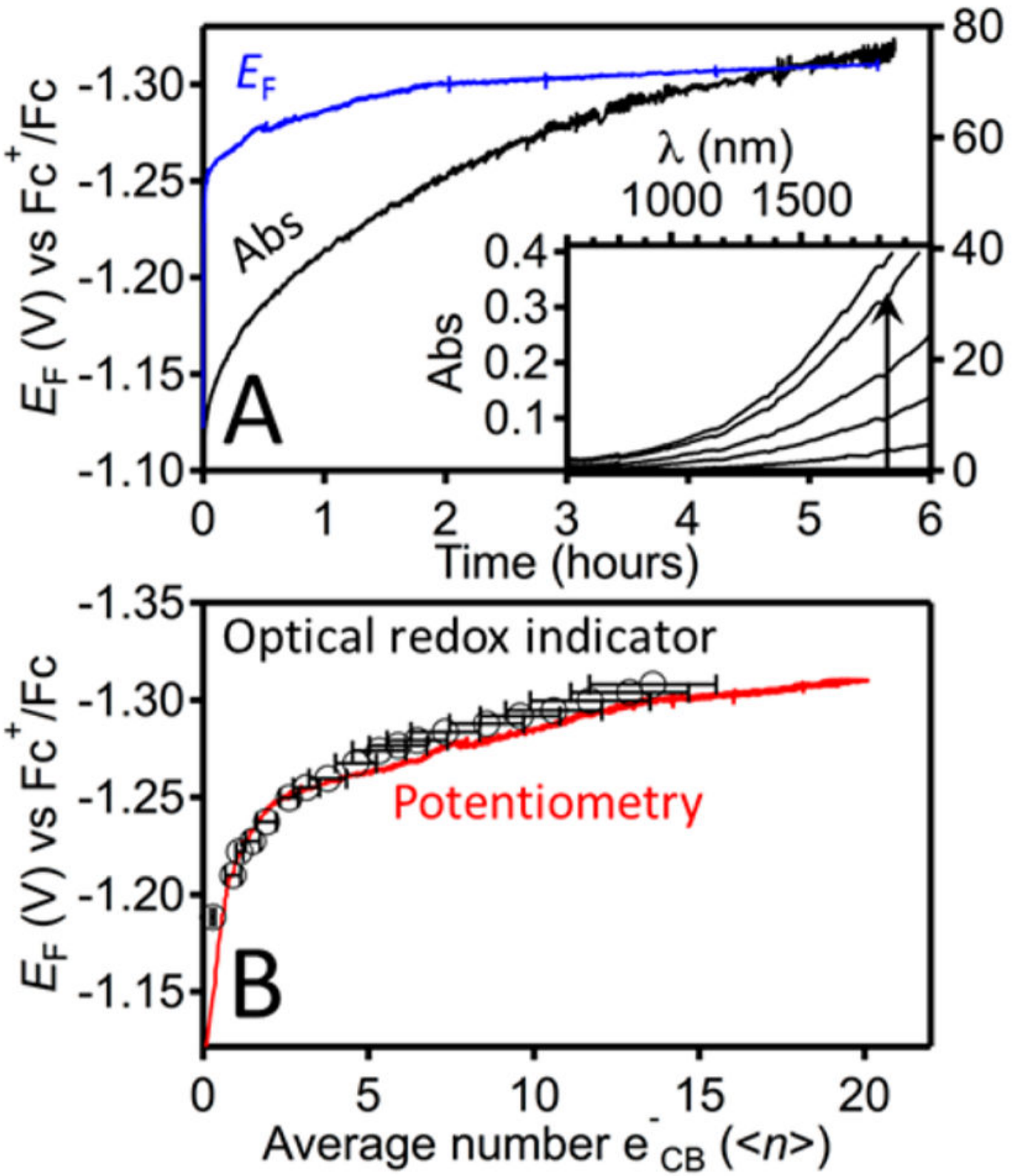

Figure 2.

(A) Potentiometry (blue) and electronic absorption (black, $\lambda=1000 \mathrm{~nm}$ ) data collected during photodoping of $d=6.8 \mathrm{~nm} \mathrm{ZnO} \mathrm{NCs}(2 \mu \mathrm{M})$ using $\mathrm{EtOH}$ as the hole quencher. A 14:1 THF/toluene solution of $0.1 \mathrm{M}$ tetrabutylammonium hexafluorophosphate $\left(\left[\mathrm{Bu}_{4} \mathrm{~N}\right]-\right.$ $\left.\left[\mathrm{PF}_{6}\right]\right), 660 \mu \mathrm{M}\left[\mathrm{Cp}_{2} \mathrm{Co}\right]\left[\mathrm{PF}_{6}\right]$ was irradiated at $340 \mathrm{~nm}(12 \mathrm{~mW})$ while stirring. The inset shows NIR absorption spectra of the same $\mathrm{ZnO}$ NCs growing with increasing $\langle n\rangle$. (B) Plot of $E_{\mathrm{F}} \mathrm{vs}\langle n\rangle$ for photodoped $\mathrm{ZnO}$ NCs derived from potentiometric (curve) and ORI (circles) methods. $\langle n\rangle$ was determined spectroscopically (see SI). The error bars represent $\pm \sigma$ from the mean. $E_{\mathrm{F}}$ is referenced to the $\mathrm{Fc}^{+} / \mathrm{Fc}$ redox couple. 

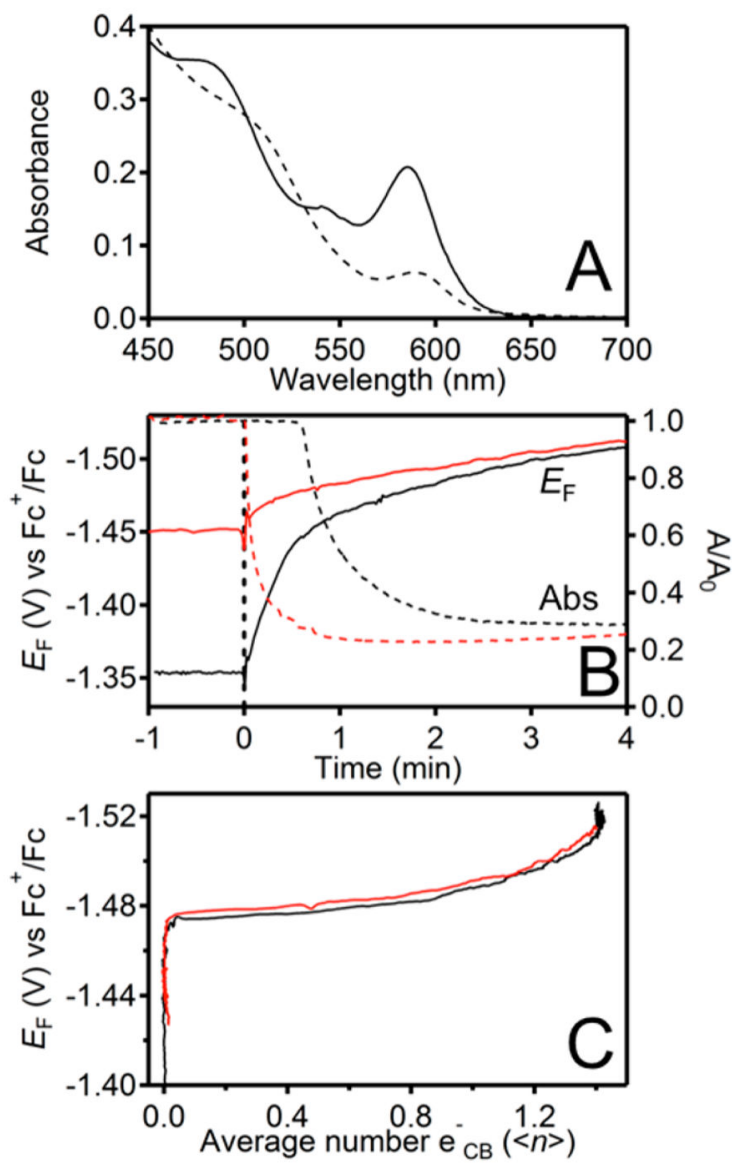

Figure 3.

(A) Electronic absorption spectra of as-prepared (solid) and photodoped (dashed) $d=4.1 \mathrm{~nm}$ CdSe NCs. Experiments were performed using a 2:1 THF:toluene solution of NCs $(0.9 \mu \mathrm{M})$, $0.05 \mathrm{M}\left[\mathrm{Bu}_{4} \mathrm{~N}\right]\left[\mathrm{PF}_{6}\right]$, and $0.15 \mathrm{M}$ trioctylphosphine oxide (TOPO). Photodoping used continuous $50 \mathrm{~mW} / \mathrm{cm}^{2} 405 \mathrm{~nm}$ irradiation and $\mathrm{Na}\left[\mathrm{Et}_{3} \mathrm{BH}\right](200 \mu \mathrm{M})$ as the hole quencher. CB electrons are compensated by $\mathrm{Na}^{+}$and $\mathrm{H}^{+.21}(\mathrm{~B})$ Transient potentiometric $\left(E_{\mathrm{F}}\right.$, solid) and excitonic absorption $\left(A / A_{0}\right.$, dashed, $\left.\lambda=590 \mathrm{~nm}\right)$ data collected simultaneously, using 0 (red) and $60 \mu \mathrm{M}$ (black) $\left[\mathrm{Cp}_{2} \mathrm{Co}\right]\left[\mathrm{PF}_{6}\right]$, before $(t<0)$ and during $(t \geq 0) 405 \mathrm{~nm}$ irradiation with constant stirring. $E_{\mathrm{F}}$ is referenced to the $\mathrm{Fc}^{+} / \mathrm{Fc}$ couple. (C) Plot of $E_{\mathrm{F}} \mathrm{vs}\langle n\rangle$ from the data of panel B. $\langle n\rangle$ was calculated from $\langle n\rangle=2\left(1-A / A_{0}\right)$. 


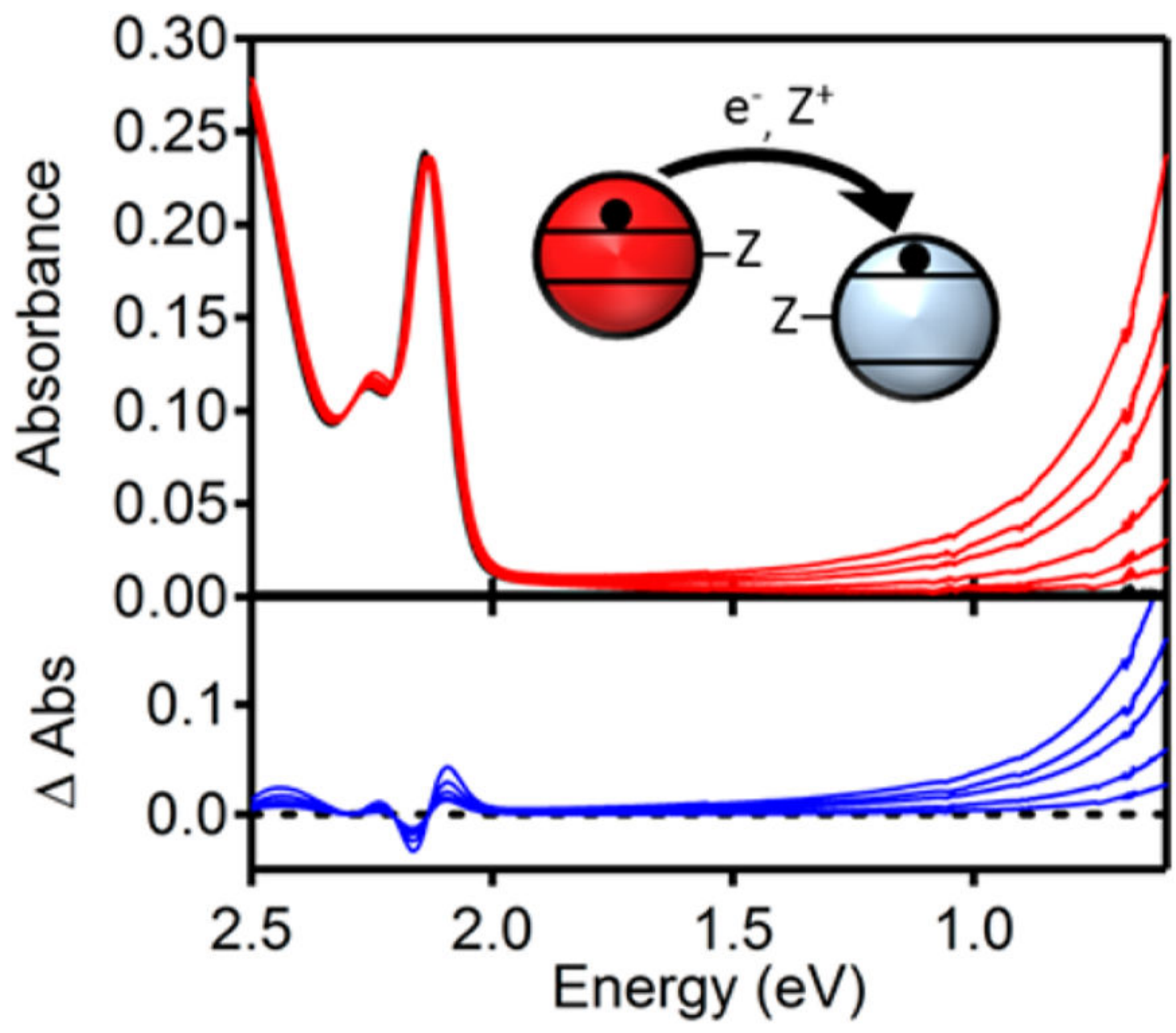

Figure 4.

Top: Electronic absorption spectra of a mixture of $d=3.8 \mathrm{~nm}$ CdSe NCs $(1.25 \mu \mathrm{M}), d=9.6$ $\mathrm{nm} \mathrm{ZnO} \mathrm{NCs}(2 \mu \mathrm{M})$, and $\mathrm{Li}\left[\mathrm{Et}_{3} \mathrm{BH}\right](660 \mu \mathrm{M})$, collected after various durations of selective CdSe NC photoexcitation (broad-band, $\lambda>480 \mathrm{~nm}$ ). Bottom: Difference spectra $\left(A-A_{0}\right)$. For clarity, the data are plotted against energy $(\mathrm{eV})$. 